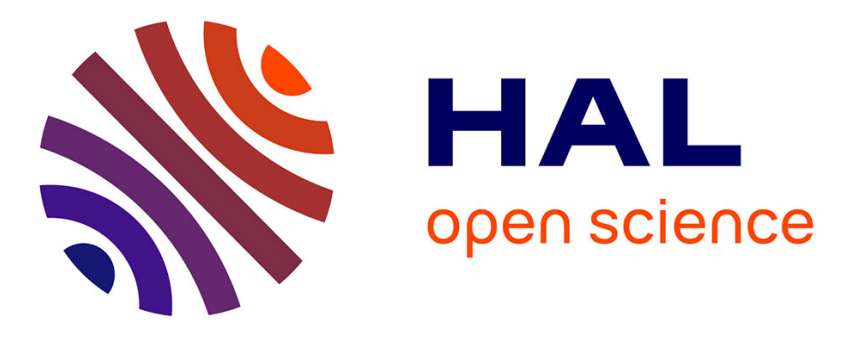

\title{
An oxidatively damaged G-quadruplex/hemin DNAzyme
}

Jiawei Wang, Mingpan Cheng, Jielin Chen, Huangxian Ju, David Monchaud, Jean-Louis Mergny, Jun Zhou

\section{- To cite this version:}

Jiawei Wang, Mingpan Cheng, Jielin Chen, Huangxian Ju, David Monchaud, et al.. An oxidatively damaged G-quadruplex/hemin DNAzyme. Chemical Communications, 2020, 56 (12), pp.1839-1842. 10.1039/C9CC09237D . hal-02475237

\section{HAL Id: hal-02475237 https://hal.science/hal-02475237}

Submitted on 18 Feb 2020

HAL is a multi-disciplinary open access archive for the deposit and dissemination of scientific research documents, whether they are published or not. The documents may come from teaching and research institutions in France or abroad, or from public or private research centers.
L'archive ouverte pluridisciplinaire HAL, est destinée au dépôt et à la diffusion de documents scientifiques de niveau recherche, publiés ou non, émanant des établissements d'enseignement et de recherche français ou étrangers, des laboratoires publics ou privés. 


\title{
An oxidatively damaged G-quadruplex/hemin DNAzyme
}

\author{
Jiawei Wang, ${ }^{a}$ Mingpan Cheng, ${ }^{a}$ Jielin Chen, ${ }^{a}$ Huangxian Ju, ${ }^{a}$ \\ David Monchaud, ${ }^{\mathrm{b}}$ Jean-Louis Mergny ${ }^{\mathrm{a}, \mathrm{c}}$ and Jun Zhou*a
}

\begin{abstract}
a State Key Laboratory of Analytical Chemistry for Life Science, School of Chemistry and Chemical Engineering,

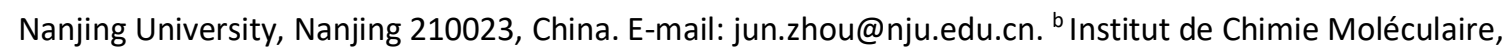
Université de Bourgogne (ICMUB), CNRS UMR6302, UBFC Dijon 21000, France. ' Institut Curie, Université Paris Saclay, CNRS-UMR 9187, INSERM U1196, F-91405 Orsay, France.
\end{abstract}

\begin{abstract}
Oxidative damage of guanine to 8-oxoguanine triggers a partial and variable loss of Gquadruplex/hemin DNAzyme activity and provide clues about the mechanistic origins of DNAzyme deactivation, which originates in an interplay between decreased G-quadruplex stability, lower hemin affinity and a modification of the nature of hemin binding site.
\end{abstract}

G-quadruplexes (G4s), assembled by four Gs in the same plane and more quarters subsequently self-stack via $\pi$-stacking interactions (Fig. 1), have recently attracted great interest for their possible biological roles, given that they are widely distributed in the human genomes and transcriptomes ${ }^{1-4}$. G4s are also key players in biotechnology: thanks to their controllable stability and polymorphism ${ }^{5}$. G4s have been instrumental in the development of a new class of functional nucleic acids, chiefly the G4-DNAzymes (Fig. 2) ${ }^{5-8}$. The exquisite interaction between G4s and hemin (iron (III)-protoporphyrin IX) results in peroxidasemimicking G4-DNAzyme systems ${ }^{9}$, which have been used as biosensors ${ }^{10,11}$ and biodevices ${ }^{5,12,13}$. Over the past years, various strategies have been applied to enhance the enzymatic proficiency of G4-DNAzymes, including the addition of a proximal adenine or cytosine nucleotide to the $3^{\prime}$ G-quartet of a parallel G4 (the preferential hemin binding site) ${ }^{14-21}$, the covalent linking of a substrate aptamer to $\mathrm{G} 4$ sequences ${ }^{22-24}$, or the addition of small-molecular catalytic enhancers ${ }^{25-30}$. 


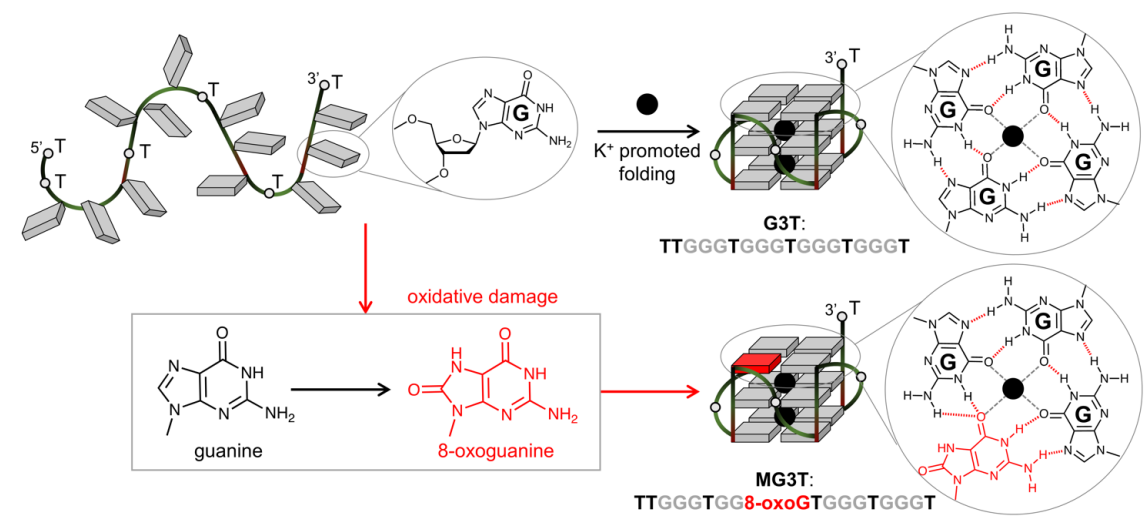

Fig. 1 Schematic representation of a parallel quadruplex-forming sequence (here, $T_{2} G_{3} T_{3} T G_{3} T G_{3} T$ ) under its unfolded (left) and $\mathrm{K}^{+}$-promoted folded structure (i.e., a G-quadruplex, or G4, right), with detailed chemical structure of a guanine $(G)$ and a G-quartet (right). Lower panel: oxidative damage of a guanine (G), converted into an 8-oxoguanine (8-oxoG), and consequences for the formation of an 8-oxoG-containing G-quartet.

Interestingly, most if not all G4-DNAzymes described to date are fueled by hydrogen peroxide $\left(\mathrm{H}_{2} \mathrm{O}_{2}\right)$ as the stoichiometric oxidant ${ }^{9}$. In living organisms, $\mathrm{H}_{2} \mathrm{O}_{2}$ is known to oxidize DNA, notably converting Gs into 8-oxoguanine (8-oxoG, Fig. 1) ) $^{31-34}$. It was thus of interest to study the possible side-effect of $\mathrm{H}_{2} \mathrm{O}_{2}$ on the structural integrity of the $\mathrm{G} 4$ pre-catalyst. First insights have been provided by Sen et al. who showed by a combination of chemical probing and electron paramagnetic resonance (EPR) that $\mathrm{G} 4 \mathrm{~s}$ are indeed damaged by $\mathrm{H}_{2} \mathrm{O}_{2}$, likely to be responsible for the inactivation of DNAzyme activity ${ }^{35}$. More recently, Podbevsek et al. reported that a G4 structure is stable enough to tolerate a substitution of a guanine by an 8$\mathrm{oxoG}^{36}$.

We thus decided to systematically investigate the impact of oxidative lesions on enzymatic activity of parallel G4/hemin DNAzymes (Fig. 2). To this end, we designed a series of eleven G4forming sequences without (controls) and with 8-oxoGs at various positions within the sequences belonging to the 3 '-end quartet, the preferred hemin binding pocket (Fig. 2, Table 1); G4s with 8-oxoG located on the 5'-end and in the middle quartets were used as controls, as shown below. Three unmodified sequences were used as controls: G3T and the two related G3TC and G3A, in which a d(C) was added at the 3'-end (G3TC) or in which the final $d(T)$ was replaced by a $d(A)(G 3 A)$. G3T was selected as a model G4 given that its structure has been confirmed by nuclear magnetic resonance (NMR) spectroscopy (parallel G4, PDB ID: 2LK7) ${ }^{37}$. 8oxoG were introduced at positions 5, 9, 13 and 17 of both G3TC and G3A, thus providing a series of eight oxidatively modified sequences referred to as TC-5, TC-9, TC-13, TC- 17, A-5, A9, A-13, A-17, respectively (Fig. 2, Table 1). 


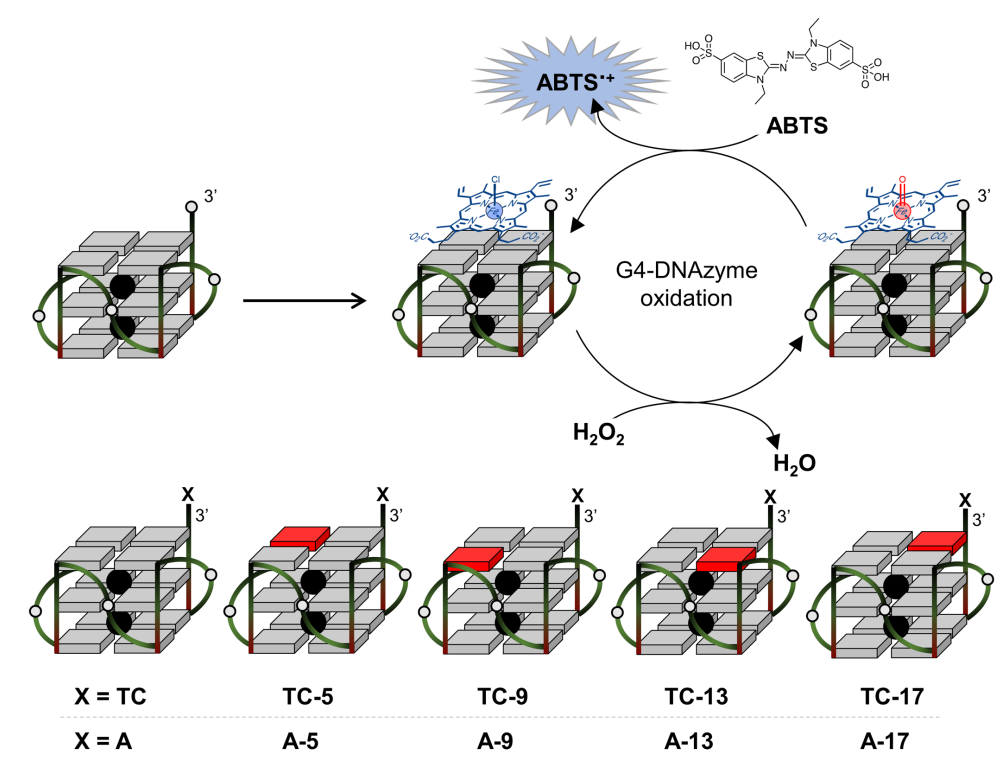

Fig. 2 Schematic representation of a G4/hemin DNAzyme system (upper panel) that triggers $\mathrm{H}_{2} \mathrm{O}_{2}$-promoted oxidation of ABTS, and of 8-oxoG-containing G4s investigated in this study (8-oxoG in red, lower panel).

To demonstrate that all sequences adopt a G4 structure, thermal difference spectra (TDS) ${ }^{38}$ were recorded. As seen in Fig. 3a, all folded sequences exhibited positive and negative peaks at 279 and $295 \mathrm{~nm}$, respectively, in agreement with G4 formation, with or without oxidative damage. These results were consistent with previous reports that G4s can withstand G-to-8oxoG mutations ${ }^{36,39,40}$. Next, circular dichroism (CD) spectra showed that the incorporation of 8-oxoG in G3TC and G3A preserved the parallel topology of the parent sequences, as evidenced by positive and negative peaks at ca. 265 and ca. $242 \mathrm{~nm}$, respectively (Fig. 3b) ${ }^{39-41}$. The thermal stabilities of the resulting G4s were determined by UV-melting/annealing experiments (Fig. S1, Supporting Information): the melting temperature values ( $T_{m}$, summarized in Table 1$)$ were in line with previous reports ${ }^{36,39,40}$ that the presence of an 8-oxoG within a G4-forming sequence decreased the overall stability of the resulting G4 structure. Our results also highlight that G4s with a single 8-oxoG are quite stable, with $T_{m}$ values $>52{ }^{\circ} \mathrm{C}$. Additionally, the four G3TC-related G4s have similar stabilities, as well as the four G3A-related G4s, which is suggestive of a similar hydrogen bonding network in these structures. Collectively, these results show that the 8oxoG-modified G4s studied here tolerate oxidative damage of the guanine residues, both in terms of topology (a parallel fold is preserved) and stability ( $T_{m}$ decreased moderately and still above physiological temperature). As demonstrated by previously reported high-resolution structures (PDB IDs: 6IAO, 6IA4) ${ }^{36}$, this stability could originate in the involvement of the oxygen of $\mathrm{C}_{6}=\mathrm{O}_{6}$ from the 8-oxoG in two $\mathrm{H}$-bonds with the proximal $\mathrm{G}$ (Fig. 1), thereby participating to the stability of the $8-\mathrm{oxo} G \bullet \mathrm{G} \bullet \mathrm{G} \bullet \mathrm{G}$ quartet, yet less stable than the native $\mathrm{G} \bullet \mathrm{G} \bullet \mathrm{G} \bullet \mathrm{G}$ quartet. 
Table 1 DNA sequences information ${ }^{a}$

\begin{tabular}{|c|c|c|c|}
\hline Name & Sequences $\left(5^{\prime} \rightarrow 3^{\prime}\right)$ & $T_{m}\left({ }^{\circ} \mathrm{C}\right)^{b}$ & $\mathrm{~V}_{\mathrm{o}}(\mathrm{nM} / \mathrm{s})^{c}$ \\
\hline \multicolumn{4}{|c|}{ Unmodified } \\
\hline & $17^{d}$ & & \\
\hline G3T & TT GGG T GGG T GGG T GGG T & $>85$ & $28.8 \pm 1.9$ \\
\hline G3TC & TT GGG T GGG T GGG T GGG TC & $>85$ & $276.7 \pm 22.7$ \\
\hline \multirow[t]{2}{*}{ G3A } & TT GGG T GGG T GGG T GGG A & $>85$ & $125.5 \pm 17.0$ \\
\hline & Modified by 8-oxoG & & \\
\hline TC-5 & TT GGX T GGG T GGG T GGG TC & 55.1 & $120.9 \pm 3.6$ \\
\hline TC-9 & TT GGG T GGX T GGG T GGG TC & 52.4 & $189.5 \pm 21.3$ \\
\hline TC-13 & TT GGG T GGG T GGX T GGG TC & 54.1 & $221.6 \pm 21.6$ \\
\hline TC-17 & TT GGG T GGG T GGG T GGX TC & 54.2 & $57.6 \pm 4.6$ \\
\hline$A-5$ & TT GGX T GGG T GGG T GGG A & 58.0 & $59.6 \pm 4.7$ \\
\hline$A-9$ & TT GGG T GGX T GGG T GGG A & 57.7 & $87.8 \pm 11.3$ \\
\hline A-13 & TT GGG T GGG T GGX T GGG A & 57.3 & $99.4 \pm 13.1$ \\
\hline A-17 & TT GGG T GGG T GGG T GGX A & 58.0 & $73.3 \pm 4.5$ \\
\hline
\end{tabular}

${ }^{a} \mathrm{X}$ indicates that guanine is replaced by 8-oxoG. ${ }^{b} T_{m}$ is obtained from the UV-melting experiments (Fig. S1). ${ }^{c}$ Initial reaction velocity $\left(\mathrm{V}_{\mathrm{o}}\right)$ is obtained from the DNAzyme activity assay (Fig. S2). ${ }^{d}$ Nucleotide position.

In our modified sequences, G-to-8-oxoG substitutions are located at the 3' quartet, i.e., close to the hemin binding site. We thus decided to assess whether and how the presence of 8- oxoG affects the catalytic proficiency of the resulting G4s. To this end, we implemented the wellstudied oxidation of 2,2'-azino-bis(3-ethylbenzothiazoline-6-sulphonic acid) (ABTS) by $\mathrm{H}_{2} \mathrm{O}_{2}$ as a model reaction. This reaction provides an easily readable output, the evolution of absorbance of the oxidized product ABTS ${ }^{+}$at $\lambda=420 \mathrm{~nm}$ as a function of time (Fig. S2). Several conclusions can be drawn from the initial reaction velocities $\left(V_{o}\right)$, presented in Fig. 4a: $i$ - the addition of $d(T C)$ or $d(A)$ at $3^{\prime}$ end of a G4 improves its activity $\left(V_{0}=29,277\right.$ and $126 \mathrm{nM} / \mathrm{s}$ for G3T, G3TC and G3A, respectively), which is consistent with previous reports ${ }^{15-19}$; $i i$ - the presence of 8-oxoG decreases the catalytic efficiency (e.g., $\mathrm{V}_{\mathrm{o}}=121$ and $59 \mathrm{nM} / \mathrm{s}$ for TC-5 andA-5, respectively); but iii- the activity of 8-oxoG-modified G4s is still noticeable, being higher than that of hemin alone (blank, $\left.\mathrm{V}_{\mathrm{o}}=1.1 \mathrm{nM} / \mathrm{s}\right)$ and of the parent G3T $\left(\mathrm{V}_{\mathrm{o}}=29 \mathrm{nM} / \mathrm{s}\right)$. The position of the 8-oxoG modification influences the catalysis (Fig. 4b), with lower catalytic efficiency for G4 bearing modifications close to $3^{\prime}$ end of $d(T C)$ and $d(A)$ tails, $\left(V_{0}=121,58,60\right.$ and $73 \mathrm{nM} / \mathrm{s}$ for TC-5, TC$17, A-5$ and $A-17$, respectively) as compared to $G 4 s$ with modifications away from the tails $\left(V_{0}\right.$ $=190,223,88$ and $99 \mathrm{nM} / \mathrm{s}$ for TC-9, TC-13, A-9 and A-13, respectively). To gain further insights 
into the possible roles of oxidized Gs on catalysis, 8-oxoG were introduced both on the 5 '-end (TC-15, Fig. S3) and in the middle G-quartet (TC-16, Fig. S3), which are not supposed to interact directly with hemin. Both sequences form G4 structures, as evidenced by TDS and CD, but TC15 was found far more stable than TC-16 ( $T_{\mathrm{m}}=55$ and $42^{\circ} \mathrm{C}$, respectively, Fig. S3). The performance of TC-15 was comparable to that of the parent G3TC ( $V_{0}=259$ and $277 \mathrm{nM} / \mathrm{s}$, respectively), in line with the preferential hemin binding site located on the $3^{\prime}$-end quartet ${ }^{14-21}$. The catalytic proficiency of TC-16 was weak $\left(V_{o}=117 \mathrm{nM} / \mathrm{s}\right)$, which may originate from its low thermal stability.

(a)

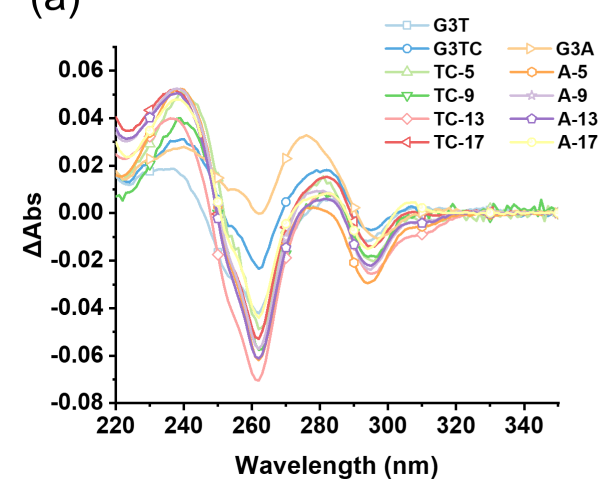

(b)

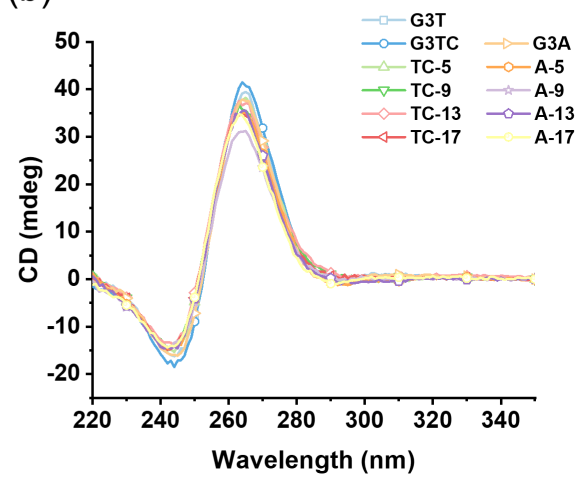

Fig. 3 Evidence for G-quadruplex formation. (a) Thermal difference spectra (TDS) of all sequences. Unless otherwise stated, UV-visible absorbance spectra were carried out in $10 \mathrm{mM} \mathrm{pH} 7.0$ Tris- $\mathrm{HCl}$ containing $50 \mathrm{mM}$ $\mathrm{KCl}$ and $5.0 \mu \mathrm{M}$ DNA. TDS were the differences of absorbance between the high and low temperatures. Potassium concentration in solution was decreased to $5.0 \mathrm{mM}$ because of the extremely high stabilities of G3T, G3A and G3TC. (b) CD spectra of all sequences in the presence of $50 \mathrm{mM} \mathrm{KCl}$.

(a)

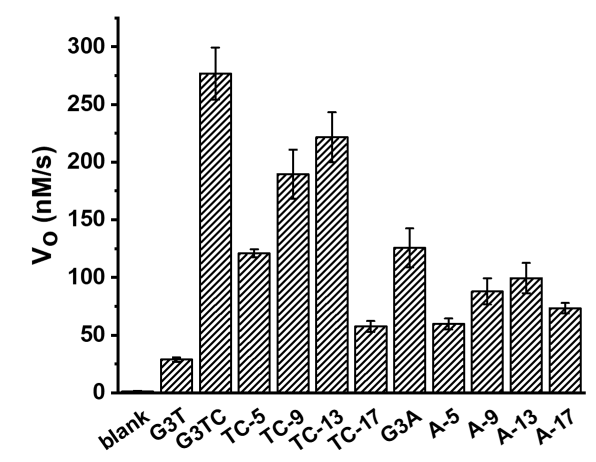

(b)

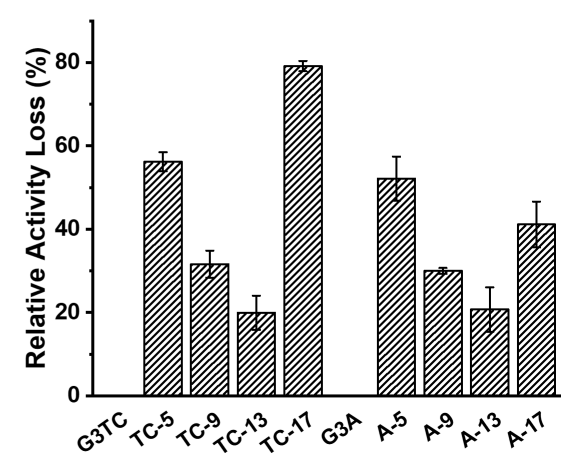

Fig. 4 Catalytic activities of DNAzyme without or with an oxidative lesion. (a) Initial reaction velocities $\left(V_{0}\right.$, $\mathrm{nM} / \mathrm{s}$ ). Raw data are presented in Fig. S2. 'Blank' represents the $V_{o}$ of hemin alone. Reaction conditions: $0.8 \mu \mathrm{M}$ DNA, $0.4 \mu \mathrm{M}$ hemin, $0.05 \%$ Triton X-100, $2.0 \mathrm{mM}$ ABTS and $0.6 \mathrm{mM} \mathrm{H}_{2} \mathrm{O}_{2}, 10 \mathrm{mM} \mathrm{pH} \mathrm{7.0} \mathrm{Tris-HCl} \mathrm{containing} 50$ $\mathrm{mM} \mathrm{KCl}, 25^{\circ} \mathrm{C}$. Error bars represented the standard deviation in three independent experiments. (b) Relative activity $\left(V_{0}\right)$ loss after modification of G-quadruplexes, compared to the parent G3TC or G3A sequence, with no oxidation product. 
Mechanistically, the activity of G4-DNAzyme complexes relies on the transient formation of high valent iron after the addition of $\mathrm{H}_{2} \mathrm{O}_{2}$ (Fig. 5a). These unstable intermediates can either oxidize ABTS (to form $\mathrm{ABTS}^{+}$) or degrade the G4/hemin complex, or both. This was investigated by UV-Vis spectroscopy: a sharp Soret band (absorbance at $\lambda=404 \mathrm{~nm}$ ) belonging to the hemin spectra appears upon addition of G4s (Fig. S4), indicating that both unmodified and modified G4s can coordinate the ferric ion. The degradation of $\mathrm{G} 4 /$ hemin complex by $\mathrm{H}_{2} \mathrm{O}_{2}$ was monitored via the time-dependent evolution of this Soret band in the absence of ABTS (Fig. 5a and S5): the good correlation between the apparent initial degradation rates ( $V_{d}$, Fig. $5 b$ ) and $V_{o}$ suggests that both unmodified and modified G4s activate hemin via a similar coordination pattern. These results showed again that modifications close to the sequence tails impair the catalytic activity of the resulting G4s more than modifications in the central positions (e.g., $\mathrm{V}_{\mathrm{d}}$ = 4.6, 3.1 and 6.9, 7.2 nM/s for TC-5, TC-17 and TC-9, TC-13, respectively). Finally, the binding affinity $\left(K_{\mathrm{a}}\right)$ of hemin for G4s determined via UV-Vis titration (Table S1, Fig. 5b) demonstrated that 8-oxoG modifications decrease binding affinity, which may also contribute to the global loss of DNAzyme activity. Our results are in line with previous reports notably from Sen et al. who detected an oxidatively damaged $\mathrm{G}$ in a $\mathrm{G} 4 /$ hemin complex upon addition of $\mathrm{H}_{2} \mathrm{O}_{2}{ }^{36}$, and Shangguan et al. who demonstrated that the inactivation of $\mathrm{G} 4 /$ hemin complex can be mainly attributed to the hemin degradation by $\mathrm{H}_{2} \mathrm{O}_{2}{ }^{42}$. We confirm that oxidative damage of $\mathrm{G} 4$ results in partial G4-DNAzyme inactivation (20-80\%, Fig. 4b) and that both $\mathrm{H}_{2} \mathrm{O}_{2}$-mediated degradation of hemin and oxidation of G4s contribute to the overall inactivation of the G4-DNAzyme system (Fig. 5a).

(a)

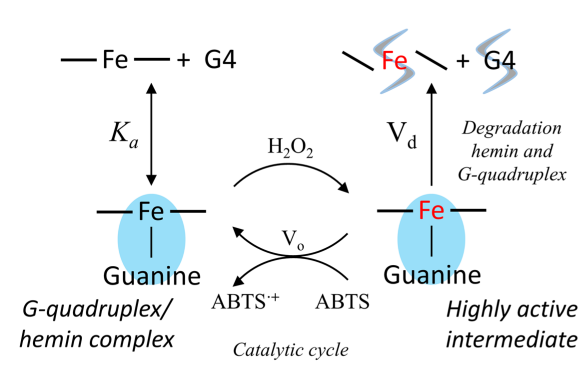

(b)

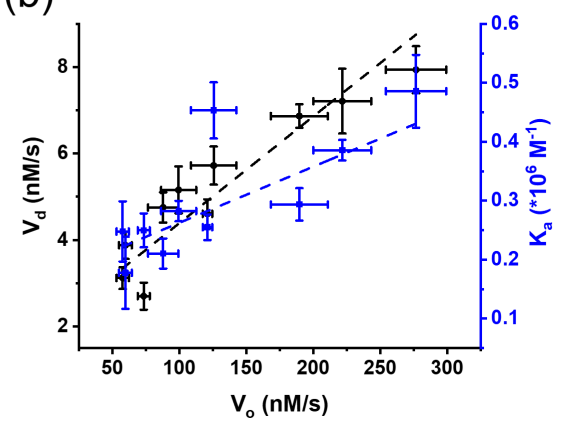

Fig. 5 (a) Scheme of the interaction between G-quadruplex and hemin $\left(K_{a}\right)$, catalytic cycle $\left(V_{o}\right)$ and degradation of G-quadruplex/hemin complex $\left(V_{d}\right)$ in the absence of reductant substrate. Inactivation results from the degradation of both hemin and G-quadruplex. (b) Apparent initial reaction velocity $\left(\mathrm{V}_{\mathrm{o}}\right)$ as functions of initial degradation velocity ( $V_{d}$, black dot and left scale) and apparent binding constant between $G$-quadruplex and hemin ( $K_{a}$, blue square and right scale). $V_{o}$ was extracted from the above mentioned activity assay (Fig. S2). $V_{d}$ is the initial degradation rate of $\mathrm{G}$-quadruplex/hemin complex by $\mathrm{H}_{2} \mathrm{O}_{2}$ in the absence of reductant substrate (Fig. S5). 
(a)

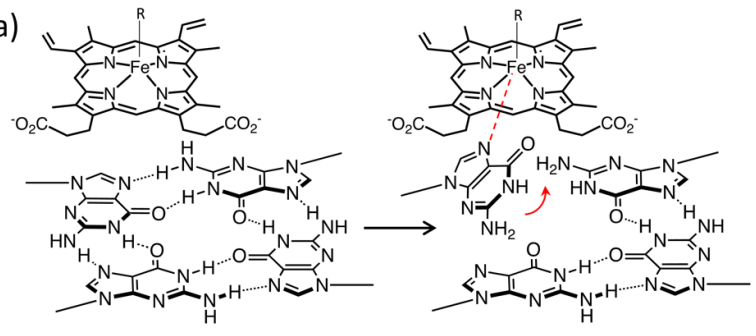

(b)

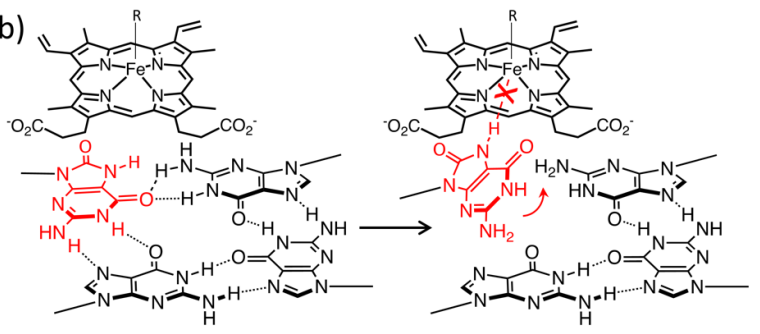

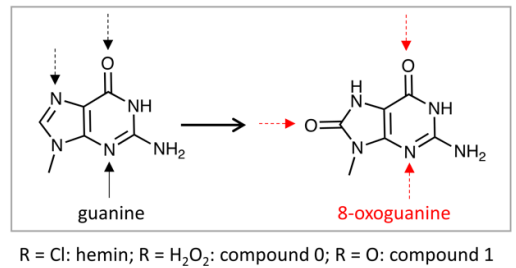

(c)
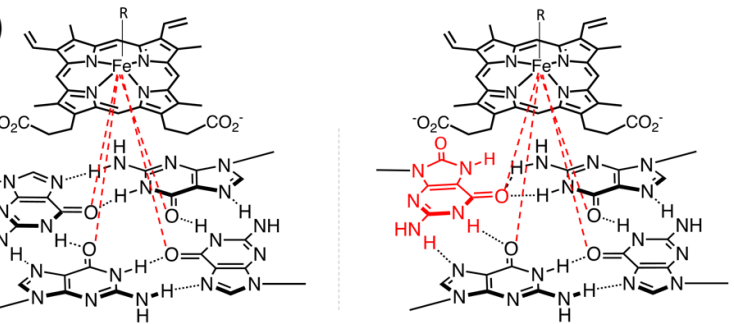

Fig. 6 Postulated intermediate for G4-DNAzyme catalysis: the guanine flipping model $(\mathbf{a}, \mathbf{b})$ versus the pancoordination model (c). Inset: schematic representation of the coordination possibilities of $G$ and 8-oxoG (arrows).

Finally, we analysed the coordination properties of both $G$ and 8-oxoG. As seen in Fig. 6, while both of them have three possible coordination sites (dashed arrows), the most notable difference concerns the $\mathrm{N}_{7}$-coordination, which is blocked in 8-oxoGs. This may have important consequence for coordinating hemin during the catalysis. Indeed, two catalytic intermediate models are currently postulated (Fig. 6a-c): in the first model, a G can transiently flip out from the G-quartet plane $\mathrm{e}^{19,26,35,43-45}$ to coordinate the iron atom and activate it; in the second model, the iron atom coordination occurs via the oxygen atoms of the four carbonyl groups without G-quartet disruption. Our results suggest the reliability of the first model (Fig. 6b): even if the 8-oxoG can flip out of the modified G-quartet, it will not coordinate properly the iron atom given that its $N_{7}$ position three $G$ can still coordinate to iron for the formation of activity intermediates. For the second model, the coordination between oxygen and iron seems to be not affected the modification of G-quartet (Fig. 6c), which is not compatible with activity loss herein. Of note, another possible explanation could involve a strand-slipped intermediate, ${ }^{46}$ but no information has yet been collected to support it during DNAzyme-type catalysis.

Collectively, the sequential G-to-8-oxoG modification strategy described here confirms that DNA oxidation globally alters the catalytic proficiency of G4-based DNAzyme. They also provide invaluable insights into the mechanistic origins of activity loss, which seems to result from an interplay between decreased G4 stability, lower hemin affinity and a modification of the nature of the hemin binding pocket. Our results favour a guanine-flipping model, which is close to 
what has been recently demonstrated as a naturally-occurring intermediate of G4-resolving helicase. This demonstration has profound implications for the design of ever-more efficient and stable G4-DNAzyme systems, which should now embed structurally flexible external quartet to allow for an optimized activation of the hemin iron atom while maintaining good $\pi$ staking interactions with the macrocyclic scaffold of the hemin. This represents a novel example of a finely tuned and highly sophisticated mechanism that nature was able to create.

We acknowledge the financial support of the National Natural Science Foundation of China (21977045 and 21503229), the funds of Nanjing University (020514912216), and self-funding projects from State Key Laboratory of Analytical Chemistry for Life Science, Nanjing University (5431ZZXM1905).

\section{Conflicts of interest}

The authors declare no conflict of interest.

\section{Notes and references}

1 A. Bedrat, L. Lacroix and J. L. Mergny, Nucleic Acids Res., 2016, 44, 1746-1759.

2 V. S. Chambers, G. Marsico, J. M. Boutell, M. Di Antonio, G. P. Smith and S. Balasubramanian, Nat. Biotechnol., 2015, 33, 877-881.

3 C. K. Kwok, G. Marsico, A. B. Sahakyan, V. S. Chambers and S. Balasubramanian, Nat. Methods, 2016, 13, 841-844.

4 S.Y. Yang, P. Lejault, S. Chevrier, R. Boidot, A. G. Robertson, J. M. Y. Wong and D. Monchaud, Nat. Commun., 2018, 9, 4730.

5 J. L. Mergny and D. Sen, Chem. Rev., 2019, 119, 6290-6325.

6 M. Cheng, Y. Li, J. Zhou, G. Jia, S. M. Lu, Y. Yang and C. Li, Chem. Commun., 2016, 52, 96449647.

7 D. J. Chinnapen and D. Sen, Proc. Natl. Acad. Sci. U. S. A., 2004, 101, 65-69.

8 H. Ibrahim, P. Mulyk and D. Sen, ACS Omega, 2019, 4, 15280-15288.

9 P. Travascio, Y. Li and D. Sen, Chem. Biol., 1998, 5, 505-517.

10 L. Zhang, J. Zhou, F. Ma, Q. Wang, H. Xu, H. Ju and J. Lei, Chem. - Eur. J., 2019, 25, 490-494.

11 J. Ida, S. K. Chan, J. Glokler, Y. Y. Lim, Y. S. Choong and T. S. Lim, Molecules, 2019, 24, 1079.

12 Y. Xing, X. Liu, Q. Pu, M. Wu and J. X. Zhao, ACS Appl. Bio Mater., 2018, 1, 1019-1027.

13 R. Zhong, Q. Tang, S. Wang, H. Zhang, F. Zhang, M. Xiao, T. Man, X. Qu, L. Li, W. Zhang and H. Pei, Adv. Mater., 2018, 30, e1706887.

14 L. C. Poon, S. P. Methot, W. Morabi-Pazooki, F. Pio, A. J. Bennet, D. Sen, J. Am. Chem. Soc., 2011, 133, 1877-1884.

15 Y. Guo, J. Chen, M. Cheng, D. Monchaud, J. Zhou and H. Ju, Angew. Chem. Int. Ed., 2017, 56, 16636-16640.

16 W. Li, Y. Li, Z. Liu, B. Lin, H. Yi, F. Xu, Z. Nie and S. Yao, Nucleic Acids Res., 2016, 44, 7373-7384.

17 T. Chang, H. Gong, P. Ding, X. Liu, W. Li, T. Bing, Z. Cao and D. Shangguan, Chem. - Eur. J., 2016, 22, 4015-4021.

18 W. Li, S. Chen, D. Xu, Q. Wen, T. Yang and J. Liu, Chem. - Eur. J., 2018, 24, 14500-14505.

19 J. Chen, Y. Zhang, M. Cheng, Y. Guo, J. Šponer, D. Monchaud, J. L. Mergny, H. Ju and J. Zhou, ACS Catal., 2018, 8, 11352-11361. 
M. Cheng, J. Zhou, G. Jia, X. Ai, J. L. Mergny and C. Li, Biochim. Biophys. Acta Gen. Subj., 2017, 1861, 1913-1920.

21 J. Chen, Y. Guo, J. Zhou and H. Ju, Chem. - Eur. J., 2017, 23, 4210-4215.

22 E. Golub, H. B. Albada, W. C. Liao, Y. Biniuri and I. Willner, J. Am. Chem. Soc., 2016, 138, 164172.

23 H. B. Albada, E. Golub and I. Willner, Chem. Sci., 2016, 7, 3092-3101.

24 H. B. Albada, J. W. de Vries, Q. Liu, E. Golub, N. Klement, A. Herrmann and I. Willner, Chem. Commun., 2016, 52, 5561-5564.

25 D. M. Kong, J. Xu and H. X. Shen, Anal. Chem., 2010, 82, 6148-6153.

26 L. Stefan, F. Denat and D. Monchaud, Nucleic Acids Res., 2012, 40, 8759-8772.

27 L. Stefan, F. Denat and D. Monchaud, J. Am. Chem. Soc., 2011, 133, 20405-20415.

28 C. Qi, N. Zhang, J. Yan, X. Liu, T. Bing, H. Mei and D. Shangguan, RSC Adv., 2014, 4, 1441-1448.

29 L. Xiao, Z. Zhou, M. Feng, A. Tong and Y. Xiang, Bioconjug. Chem., 2016, 27, 621-627.

30 H. Sato, N. Shimada, T. Masuda and A. Maruyama, Biomacromolecules, 2018, 19, 2082-2088.

31 J. Zhou, A. M. Fleming, A. M. Averill, C. J. Burrows and S. S. Wallace, Nucleic Acids Res., 2015, 43, 4039-4054.

32 J. Wu, S. J. Sturla, C. J. Burrows and A. M. Fleming, Chem. Res. Toxicol., 2019, 32, 345-347.

33 S. Takahashi, K. T. Kim, P. Podbevsek, J. Plavec, B. H. Kim and N. Sugimoto, J. Am. Chem. Soc., 2018, 140, 5774-5783.

34 S. Cogoi, A. Ferino, G. Miglietta, E. B. Pedersen and L. E. Xodo, Nucleic Acids Res., 2018, 46, 661-676.

35 P. Travascio, P. K. Witting, A. G. Mauk and D. Sen, J. Am. Chem. Soc., 2001, 123, 1337-1348.

36 S. Bielskute, J. Plavec and P. Podbevsek, J. Am. Chem. Soc., 2019, 141, 2594-2603.

37 N. Q. Do and A. T. Phan, Chem. Eur. J., 2012, 18, 14752-14759.

38 J. L. Mergny, A. T. Phan and L. Lacroix, FEBS Letters, 1998, 435, 74-78.

39 V. V. Cheong, C. J. Lech, B. Heddi and A. T. Phan, Angew. Chem. Int. Ed., 2016, 55, 160-163.

40 V. V. Cheong, B. Heddi, C. J. Lech and A. T. Phan, Nucleic Acids Res., 2015, 43, 10506-10514.

41 R. Del Villar-Guerra, J. O. Trent and J. B. Chaires, Angew. Chem. Int. Ed., 2018, 57, 7171-7175.

42 X. Yang, C. Fang, H. Mei, T. Chang, Z. Cao and D. Shangguan, Chem. Eur. J., 2011, 17, 1447514484.

43 A. F. Voter, Y. Qiu, R. Tippana, S. Myong and J. L. Keck, Nat. Commun., 2018, 9, 4201.

44 I. Ourliac-Garnier, M. A. Elizondo-Riojas, S. Redon, N. P. Farrell and S. Bombard, Biochemistry, 2005, 44, 10620-10634.

45 H. Bertrand, S. Bombard, D. Monchaud and M. P. Teulade-Fichou, J. Biol. Inorg. Chem., 2007, 12, 1003-1014.

46 R. Stefl, T. E. Cheatham, N. Spacková, E. Fadrná, I. Berger, J. Koca and J. Sponer, Biophys. J., 2003, 85, 1787-1804. 